Louisiana State University

LSU Digital Commons

Faculty Publications

Department of Biological Sciences

$1-1-2014$

\title{
Strong natural selection on juveniles maintains a narrow adult hybrid zone in a broadcast spawner
}

\author{
Carlos Prada \\ Louisiana State University \\ Michael E. Hellberg \\ Louisiana State University
}

Follow this and additional works at: https://digitalcommons.Isu.edu/biosci_pubs

\section{Recommended Citation}

Prada, C., \& Hellberg, M. (2014). Strong natural selection on juveniles maintains a narrow adult hybrid zone in a broadcast spawner. American Naturalist, 184 (6), 702-713. https://doi.org/10.1086/678403

This Article is brought to you for free and open access by the Department of Biological Sciences at LSU Digital Commons. It has been accepted for inclusion in Faculty Publications by an authorized administrator of LSU Digital Commons. For more information, please contact ir@lsu.edu. 
VOL. 184, NO. 6 THE AMERICAN NATURALIST DECEMBER 2014

\title{
Strong Natural Selection on Juveniles Maintains a Narrow Adult Hybrid Zone in a Broadcast Spawner
}

\author{
Carlos Prada* and Michael E. Hellberg \\ Department of Biological Sciences, Louisiana State University, Baton Rouge, Louisiana 70803 \\ Submitted April 28, 2014; Accepted July 8, 2014; Electronically published October 17, 2014 \\ Online enhancement: appendix. Dryad data: http://dx.doi.org/10.5061/dryad.983b0.
}

\begin{abstract}
AвSTRACT: Natural selection can maintain and help form species across different habitats, even when dispersal is high. Selection against inferior migrants (immigrant inviability) acts when locally adapted populations suffer high mortality on dispersal to unsuitable habitats. Habitat-specific populations undergoing divergent selection via immigrant inviability should thus show (1) a change in the ratio of adapted to nonadapted individuals among age/size classes and (2) a cline (defined by the environmental gradient) as selection counterbalances migration. Here we examine the frequencies of two depthsegregated lineages in juveniles and adults of a Caribbean octocoral, Eunicea flexuosa. Distributions of the two lineages in both shallow and deep environments were more distinct when inferred from adults than juveniles. Despite broad larval dispersal, we also found an extremely narrow hybrid zone $(<100 \mathrm{~m})$, with coincident clines for molecular and morphological characters of the host coral and its algal symbiont. Effective dispersal estimates derived from the hybrid zone are remarkably small $(<20 \mathrm{~m})$ for a broadcast spawner. The large selection coefficient against mismatched genotypes derived from cohort data is consistent with that from field transplant experiments. Narrow hybrid zones and limited effective dispersal may be a common outcome of long periods of postsettlement, prereproductive selection across steep ecological gradients. Strong diversifying selection provides a mechanism to explain the prevalence of depth-segregated sibling species in the sea.
\end{abstract}

Keywords: prereproductive selection, microgeographic adaptation, octocoral, immigrant inviability.

\section{Introduction}

Natural selection via immigrant inviability occurs when the propagules of locally adapted populations suffer high mortality on migrating to unsuitable habitats (Nosil et al. 2005; Rundle and Nosil 2005). Immigrant inviability can be pronounced in organisms where the interval between recruitment and sexual reproduction is long, as in corals and trees (Prada and Hellberg 2013; Lindtke et al. 2014). While the effects of selection may be small over any given

* Corresponding author; e-mail: cprada1@lsu.edu.

Am. Nat. 2014. Vol. 184, pp. 702-713. (C) 2014 by The University of Chicago. 0003-0147/2014/18406-55454\$15.00. All rights reserved.

DOI: $10.1086 / 678403$ year, cumulative effects over many years before reproduction begins can generate a strong ecological filter against immigrants. Immigrant inviability can act across environmental gradients, generating clines or hybrid zones. If reproductive isolation occurs as a by-product of immigrant inviability, new species can arise by natural selection (Darwin 1859; Nosil et al. 2005; Rundle and Nosil 2005; Schluter 2009), often occurring across environmental gradients, where they generate hybrid zones (Endler 1977).

The segregation of adults of different species into different habitats is pronounced in many long-lived, sessile species with large dispersal, such as wind-pollinated trees (Paine et al. 2009; Baldeck et al. 2013) and reef corals that disperse via planktonic larvae (Goreau 1959; Kinzie 1973), but whether such segregation arises before or after recruitment remains unknown. Reciprocal transplant experiments show that adults suffer higher mortality in their nonnative habitat (Lowry et al. 2008; Marshall et al. 2010; Prada and Hellberg 2013). These studies show that adaptive divergence occurs and that selection can be strong, but the extent to which they reveal anything about the role of immigrant inviability in speciation depends on prerecruitment processes and whether reproductive isolation is complete.

Prerecruitment process, such as larval habitat choice (Connell 1972; Grosberg 1982), may cause a pattern of habitat segregation in adult populations without immigrant inviability. Larval habitat choice is pronounced in many sessile marine organisms (Carlon 2002; Baird et al. 2003), particularly in intertidal habitats (Grosberg 1982). Pre- and postrecruitment processes are not mutually exclusive, however, and while larvae may prefer a particular habitat, subsequent immigrant inviability may still operate to more completely segregate adults. Indeed, the two processes are interrelated, and postrecruitment mortality should favor habitat choice by larvae over evolutionary time (Grosberg 1981). If larvae choose their habitat and subsequent mortality is independent of habitat, then the distribution of species across habitats will be similar across 
age classes. In contrast, immigrant inviability will result in different distributions between age or size classes, as selection weeds out maladapted recruits over time. The distribution of different age/size classes across habitats can thus provide evidence as to whether pre- or postrecruitment mortality drives adult habitat segregation and whether and to what degree immigrant inviability works.

Immigrant inviability should also generate narrow hybrid zones because selection acts across environmental gradients (Endler 1975, 1977; Slatkin 1975). Habitat-mediated selection may be acute in organisms in which dispersal potential exceeds the scale of environmental change (Endler 1979), such as wind-pollinated plants and marine broadcasters with pelagic larvae. A long period (tens of years) between dispersal and the onset of reproduction should enhance the opportunity for selection to sort individuals by habitat before they reproduce (Prada and Hellberg 2013), thereby reducing the formation of hybrids.

The candelabrum coral Eunicea flexuosa is an especially suitable species in which to evaluate the role of immigrant inviability in the segregation of lineages across habitats (depths) because (1) different selective regimes associated with variation in depth occur at far smaller scales than dispersal, which appears to approximate panmixia across the Caribbean (Prada and Hellberg 2013); (2) first reproduction does not occur until $>30$ years of age (Beiring and Lasker 2000); and (3) unlike other reef taxa, fragmentation is uncommon, and age can accurately be estimated from size, making comparisons across age classes easier. Previously, we suggested that immigrant inviability might operate on habitat-segregated lineages of E. flexuosa because reciprocally transplanted adult colonies revealed adaptive differences between genetically differentiated shallow and deep populations (Prada et al. 2008; Prada and Hellberg 2013). Here we compare the distribution of these lineages in adults and juveniles at the extremes of a depth gradient in Puerto Rico. We find that while the lineages in both size classes are sorted by habitat, segregation is more pronounced in adults. We also found that the two lineages replace each other over a depth and light gradient, producing few hybrids. Clines for three morphological traits and six genetic markers are coincident. The width of the cline is extremely narrow $(<100 \mathrm{~m})$, to our knowledge the narrowest known when scaled by dispersal potential. We conclude that environmental selection largely maintains this hybrid zone and that the strong habitat selection segregates adult lineages by gradually eliminating young recruiting individuals over time. Such immigrant inviability helps to explain the abundance of depth-segregated sibling species (Knowlton 1993).

\section{Methods \\ Biology of Eunicea flexuosa}

Eunicea flexuosa is a colonial marine cnidarian that lives in association with algae of the genus Symbiodinium. Bushlike colonies $1-1.5 \mathrm{~m}$ tall form by the asexual budding of polyps (Bayer 1961). Colonies acquire their algal symbionts from the environment at the single-polyp stage shortly after larval metamorphosis (Coffroth et al. 2001). Eunicea flexuosa comprises two depth-segregated lineages, each adapted to its own depth as inferred from reciprocal transplants (Prada et al. 2008; Prada and Hellberg 2013). Each lineage maintains its own algal symbiont phylotype, even when both lineages meet at intermediate depths (Prada et al. 2014). Colonies of E. flexuosa have separate sexes, and sexual reproduction occurs through spawning of gametes that are fertilized in the water column (Beiring and Lasker 2000). Sperm and eggs are positively buoyant and, after release, rise to the surface, where fertilization more readily occurs (C. Prada, personal observation). As in other octocorals, most fertilization takes place within $30 \mathrm{~min}$ of gamete release (Alino and Coll 1989). In the closely related broadcast spawner Plexaura kuna, most mating occurs between neighboring colonies, but at least $8 \%$ of fertilization events involves colonies $>20 \mathrm{~m}$ apart (Coffroth and Lasker 1998). Gametes remain viable for at least $2 \mathrm{~h}$ after release in other free-spawning Caribbean anthozoans (Lasker et al. 1996; Levitan 2004). In Obicella annularis, which co-occurs with E. flexuosa, eggs move on average $>500 \mathrm{~m}$, and not less than $100 \mathrm{~m}$, in $100 \mathrm{~min}$ (Levitan et al. 2004). Thus, in $<2 \mathrm{~h}$ eggs commonly disperse distances greater than the transition separating shallow and deep forms $(<100 \mathrm{~m})$.

Larvae develop planktonically, and larval dispersal appears to be high; widely separated $(>1,000 \mathrm{~km})$ locations form panmictic populations (Prada and Hellberg 2013). Isolation with migration analyses suggest some introgression between the shallow and deep lineages (Prada and Hellberg 2013), but whether migration is ongoing was heretofore unknown.

\section{Sampling and Sequence Data}

To estimate variation in frequency of the two lineages among juveniles, we sampled 511 candelabrum coral colonies $<3 \mathrm{~cm}$ at Media Luna Reef, Puerto Rico $\left(17^{\circ} 56^{\prime}\right.$ $\left.04.1^{\prime \prime} \mathrm{N}, 67^{\circ} 02^{\prime} 52.5^{\prime \prime} \mathrm{W}\right)$. This same population was used to estimate the strength of selection between depth ecomorphs by replicated transplants (Prada et al. 2008; Prada and Hellberg 2013) and multiyear survivorship per size class (Prada and Hellberg 2013). Samples were collected at least $5 \mathrm{~m}$ apart to avoid sampling of clone mates. We genetically identified 437 as E. flexuosa juveniles (276 in 
shallow and 161 in deep habitats) using both the mitochondrial $m s h$ and the nuclear $i 3 p$ (see below for details). To estimate the frequencies in adults $(>50 \mathrm{~cm})$, we pooled data from our previous studies and added some new individuals. We sampled 99 and 103 adult individuals from the shallow and deep habitats, respectively. The adults came from this and previous studies: 40 from Prada et al. (2008), 38 from Prada and Hellberg (2013), and 21 new for shallow, and 44 from Prada et al. (2008), 38 from Prada and Hellberg (2013), and 21 new for deep. We used the Fisher exact test to detect frequency differences between age classes in both shallow and deep habitats.

To inspect for a possible hybrid zone between shallow and deep habitats, we sampled 159 adult colonies $(>50 \mathrm{~cm})$ of E. flexuosa at seven locations across the depth gradient in the same focal population in Puerto Rico. The linear transect was $200 \mathrm{~m}$ and varied in depth from 3 to $22 \mathrm{~m}$. At each location we collected tissue from between 14 and 38 colonies. We collected colonies at least $5 \mathrm{~m}$ apart to decrease the chance of sampling of clonemates. Previous multilocus genotyping of well over 300 colonies has not revealed any nonunique multilocus genotypes (Prada et al. 2008; Prada and Hellberg 2013). Samples were preserved in $95 \%$ (vol/vol) ethanol and stored at $-20^{\circ} \mathrm{C}$. We extracted genomic DNA from these samples using the Qiagen DNeasy Kit in accordance with the manufacture's protocols.

For each individual from this depth transect, we sequenced five nuclear markers and one mitochondrial DNA marker for the host and one chloroplast locus for the algal symbiont. We sequenced the mitochondrial msh region, which encodes an open reading frame unique to some anthozoans, using published primers (France and Hoover 2001). We also genotyped individuals at three previously described nuclear markers (Prada and Hellberg 2013): inositol 3-phosphatase (i3p), elongation factor 1 alpha (ef1a), and calcium transporter 2 (ct2). In addition, we sequenced individuals at two new nuclear markers developed from sequences generated from a partial 454 run (Prada and Hellberg 2013). One of the two regions is anonymous (locus 564), and the other is an exon-crossing intron of the glyceraldehyde-3-phosphate dehydrogenase ( $g l y 3 p$ ) homologue of the Nematostella vectensis genome. From these initial sequences, we generated the following primers: Gly3p_For1 (5'-AATGGAAAGTTGACTGGAATGG-3') and Gly3p_Rev1 (5'-GAAGCAATGTACTTGATGAGATCC-3') for the glyceraldehyde-3-phosphate dehydrogenase and EF_IB_CONT564F1 (5'-TAGCTCATTTCTCTCACTGTC ACG-3') and EF_IB_CONT564R1 (5'-AAGTGATCCAAC CTCTCATCTCG- $3^{\prime}$ ) for the anonymous marker. We also amplified the chloroplast coding area of the $p s b A$ for all colonies across the hybrid zone, as we previously found that it can differentiate among Symbiodinium phylotypes in depth-segregated species of E. flexuosa (Prada et al.
2014). We amplified samples for the $p s b A$ following protocols described elsewhere (Moore et al. 2003).

Polymerase chain reaction amplifications were performed in a Bio-Rad T100 thermal cycler with the same cycling conditions (except for the annealing temperature) for all genes: an initial denaturation cycle of $3 \mathrm{~min}$ at $95^{\circ} \mathrm{C}, 2 \mathrm{~min}$ of annealing at $50^{\circ}-56^{\circ} \mathrm{C}$, and $2 \mathrm{~min}$ of extension at $72^{\circ} \mathrm{C}$; followed by 38 cycles of $30 \mathrm{~s}$ at $95^{\circ} \mathrm{C}$, $45 \mathrm{~s}$ at $50^{\circ}-56^{\circ} \mathrm{C}$, and $45 \mathrm{~s}$ at $72^{\circ} \mathrm{C}$; and a final extension cycle of $120 \mathrm{~min}$ at $72^{\circ} \mathrm{C}$. Amplicons were directly sequenced in both directions in an ABI 3100 genetic analyzer using BigDye chemistry (ver. 3.1) and both amplification primers.

We resolved heterozygotes containing a single indel using Champuru software (Flot 2007) and cloned heterozygous individuals with multiple indels using the Invitrogen TOPO TA Cloning Kit, sequencing at least 5 clones per reaction. We edited and assembled all sequences using Geneious software (ver. 4.5.5; Drummond 2009). For sequences with multiple heterozygous sites, we resolved haplotypes using PHASE software (ver. 2.1; Stephens et al. 2001). We used a $90 \%$ probability as our cutoff, as haplotypes inferred by PHASE with a probability of $>70 \%$ accurately reflect haplotypes (Harrigan et al. 2008). We corroborated inferred haplotypes by directly cloning at least $10 \%$ of our sequences.

To assess morphological divergence among populations, we measured spindle length, calice diameter, and branch thickness. These three characters are the most divergent morphological characters between deep and shallow colonies of E. flexuosa in Puerto Rico, and each character responds to different axes of variation as revealed by principal component analysis (Prada et al. 2008). To quantify morphological variation, we bleached colonies to clear the organic material, washed them twice with distilled water, and dried them in ethanol. For each colony, we collected digital images using a Diagnostic Instrument SPOT RT Slider CCD camera attached to a Leica MZ7 stereomicroscope at the Socolofsky Microscopy Center, Louisiana State University. To estimate morphological variation across the cline, we converted continuous morphological measurements into frequency data. We used the Bernoulli function as implemented in the hybrid zone R package HZAR (Derryberry et al. 2014). For each location, we estimated the midpoint among all values, conducted Bernoulli trials to classify values below or above such midpoints, and then calculated the frequency at each location.

\section{Hybrid Zone Analyses}

To understand the structure of the hybrid zone across the depth gradient, we carried out three analyses. We first estimated clines for each marker to characterize variation 
across depth and test whether clines (both molecular and morphological) were coincident. We then used genetic markers to estimate a hybrid index, the inbreeding coefficient, and a measure of linkage disequilibrium (LD). Once we estimated the width of the hybrid zone for each marker and identified areas in which LD was highest (e.g., the center of the cline), we used the LD measure to estimate realized dispersal.

To determine the shape of each empirical cline, we used the three mathematical descriptions of Szymura and Barton (1986, 1991; appendix, available online). These equations describe a sigmoidal curve with a center (maximum slope) and two tails (one in each side) modeled as an exponential decay. The shape of the sigmoid curve is determined by the width of the cline and the position of its center. The tails of the curve are dependent on the distance between the center of the curve and the end of the tail and on the slope of the tail (Szymura and Barton 1986, 1991).

From this description, we tested five different models. The cline could have no tails, symmetrical tails, asymmetrical tails, left tail only, or right tail only. We fitted molecular and morphological clines to test these five models using a Metropolis-Hasting algorithm as implemented in the hybrid zone R package HZAR using the functions hzar.fitRequest and hzar.doFit (Maley 2012; Derryberry et al. 2014).

Because the shape of the cline can vary depending on how it is scaled, we included scaling differences in our models. Clines were scaled by the minimum $\left(P_{\min }\right)$ and maximum $\left(P_{\max }\right)$ frequencies in the cline. We divided scaling in three ways: no scale $\left(P_{\min }=0\right.$ and $\left.P_{\max }=1\right)$, empirical estimates $\left(P_{\min }=\right.$ minimum observed frequency, $P_{\max }=$ maximum observed frequency), and best fit $\left(P_{\min }\right.$ and $P_{\max }$ ). By using combinations of cline shapes (five possibilities) and scaling (three possibilities), we tested 15 different models for each cline. For each model and for each cline, we specified three independent chains for the Markov chain Monte Carlo search, each $7 \times 10^{5}$ steps long. To estimate parameters and generate the posterior distribution, we combined the chains, removed $7 \times 10^{4}$ as burn-in, and then estimated the cline parameters. To ensure convergence of the parameter estimates, we repeated the procedure described above at least three times. We recorded the corrected Akaike Information Criterion for each model within each cline and chose the one with the lowest score to infer cline width and center (table A1, available online). Frequency data and raw DNA sequences are available in the Dryad Digital Repository: http://dx .doi.org/10.5061/dryad.983b0 (Prada and Hellberg 2014). To test whether clines from different characters show concordance, we compared their confidence intervals, which were defined as 2-log-likelihood scores above and below the mean.
To calculate a hybrid index, we used loci that are fixed ( $m s h, i 3 p, c t 2$, and $g 3 p d$ ) between lineages, and we converted shallow and deep alleles into a 1 and 0 system and then scaled by dividing by 8 , so a pure shallow individual will have a score of 1 (all alleles for the four fixed loci) and a pure deep individual would have a score of 0 . To visualize the distribution of hybrids, we used the program NewHybrids (Anderson and Thompson 2002). We estimated the probability of first- and second-generation hybrids from genotypic data from all six loci across the hybrid zone. We ran NewHybrids at least four times and averaged estimates across replicates.

Once we had cline and hybrid estimates, we calculated LD between loci across the hybrid zone. Of the seven molecular markers, five (host $m s h, i 3 p$, ct2, and $g 3 p d$ and the algal $p s b A$ ) are fixed between the shallow and deep lineages. Barton and Gale (1993) suggest that dispersal $(\sigma)$ can be estimated as $\left(D r w_{1} w_{2}\right)^{1 / 2}$, where $D$ is the LD between the two markers, $w_{1}$ and $w_{2}$ refer to the cline width for each marker, and $r$ is the recombination rate. We estimated LD in Analyse software (Barton and Baird 1998) as $R_{i j}$, a pairwise LD measure standardized by allele frequencies $\left(R_{i j}=D_{i j} /\left(p_{i} q_{i} p_{j} q_{j}\right)^{1 / 2}\right)$. We also estimated inbreeding coefficients $\left(F_{\mathrm{IS}}\right)$ across the hybrid zone via maximum likelihood as implemented in Analyse. We then combined width and LD estimates at the cline center and estimated realized dispersal assuming a tension zone model. We assumed no association between markers $(r=0.5)$.

\section{Environmental Variables}

Coincidence of molecular and morphological clines with variation in environmental features may suggest hybrid zones maintained by habitat-based selection (Endler 1977; Moore and Price 1993). We estimated environmental variation across the hybrid zone by quantifying variation in depth and light. We used a Suunto Gekko Gauge Computer Console and a submersible irradiance meter (Li-Cor Biosciences LI-1400) to estimate depth and light, respectively. We graphed downwelling irradiance profiles to document light variation across depth. We corrected values by light measurements in air with an external collector for cloud corrections. Each measure was taken at least four times during 2007 to capture the variability in rainy and sunny seasons.

\section{Selection and Microgeographic Adaptation Analysis}

To estimate selection against genotypes in mismatched depths, we measured the frequency of juveniles and adults of the two ecotypes in both shallow and deep environments. We estimated the change in frequency relative to the change in frequency of the most common genotype 
in a given depth and subtracted the value from 1 (Hartl 2000). For example, in shallow areas the fitness of the shallow lineage is 1 , and the fitness of the deep lineage is the ratio of the frequency change between the deep and the shallow minus 1 .

To estimate the spatial scale of the adaptation $(d)$ between the shallow and the deep lineage, given the dispersal potential of the species we used the widest cline width estimate $(78 \mathrm{~m})$ and divided by the dispersal neighborhood distance of the species. We estimated the dispersal neighborhood distance $(\sigma)$ using Rosset's (1997) approach:

$$
\sigma=\left(\frac{1}{4 D_{\mathrm{e}} m}\right)^{1 / 2},
$$

where $D_{\mathrm{e}}$ is the effective density and $m$ is the slope between geographical distance and $F_{\mathrm{ST}} /\left(1-F_{\mathrm{ST}}\right)$. To estimate $m$, we averaged $F_{\mathrm{ST}}$ across four loci for populations across the Caribbean (Prada and Hellberg 2013) and estimated geographical distance among populations in Google Earth (ver. 6.2) using the shortest nautical distance. To estimate $D_{\mathrm{e}}$, we used earlier estimates of the effective population size $\left(N_{\mathrm{e}}\right)$ for $E$. flexuosa (Prada and Hellberg 2013) derived from isolation with migration analysis (Hey and Nielsen 2004). We then estimated the number of effective individuals per area using the total Caribbean coral reef area of $26,000 \mathrm{~km}^{2}$ (Burke and Maidens 2004) as a proxy for the area occupied. Because this underestimates effective density $\left(D_{\mathrm{e}}\right)$, we also estimated $D_{\mathrm{e}}$ assuming that the species uses only $10 \%$ of reef habitat. This approach renders an effective density $\left(D_{\mathrm{e}}\right)$ that ranges between 7.69 and 76.90 individuals per square kilometer. We additionally estimated effective density $\left(D_{\mathrm{e}}\right)$ using our direct estimate of the highest number of colonies per meter. Decreasing the amount of area occupied by the species and assuming a high population density bias estimates to the lowest dispersal for a species that has no significant Caribbean-wide subdivision.

\section{Results}

\section{Adults Show Stronger Habitat Segregation than Juveniles}

We collected genetic data from 437 juveniles (276 in shallow and 161 in deep habitats) and 202 adults (99 in shallow and 103 in deep habitats) of Eunicea flexuosa. Segregation was evident in both juvenile and adults but was stronger in adults (fig. $1 ; P<.001$ for shallow and $P<.01$ for deep habitats).

\section{habitat}

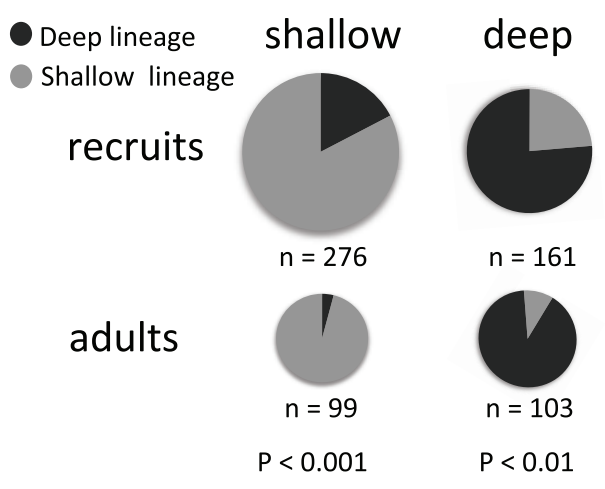

Figure 1: Frequencies of shallow (light gray) and deep (dark gray) lineages of Eunicea flexuosa at the extremes of the depth gradient. We used the Fisher exact test to estimate differences between juvenile and adult frequencies. Genetic clines were estimated using the frequency of the most common allele.

\section{Clines Are Narrow, Sigmoidal, and Coincident across Molecular and Morphological Markers}

We collected morphological and genetic data from 159 adults over a depth gradient. We found a transition in morphological and allele frequencies of both coral and algae (fig. 2). The hybrid zone between the shallow and deep forms of E. flexuosa occurred over $<77 \mathrm{~m}$ (table 1). The maximum likelihood fitted cline for half of the markers was a sigmodal model without tails and fixed frequencies (fig. 2). A left-tail model with fixed frequencies was a better fit for locus $p s b A$ (table A1, available online). All clines-molecular and morphological-for both host and algal symbiont coincided at the cline center (table 1). The 2-loglikelihood intervals of all cline centers overlapped, ranging from 116 to $130 \mathrm{~m}$ along the linear transect.

\section{$L D$ Is Highest at the Hybrid Zone Center}

Estimates of inbreeding $\left(F_{\mathrm{IS}}\right)$ and scaled LD $\left(R_{i j}\right)$ increased at the center of the hybrid zone. Our ML estimate of $F_{\mathrm{IS}}$ showed a significant heterozygote deficit at the center of the hybrid zone: while $F_{\text {IS }}$ values were near 0 at the transect extremes, they increased at 116 and $125 \mathrm{~m}$ for all loci (fig. $3 A$ ). LD also increased substantially at the center of the hybrid zone (fig. $3 B$ ), peaking at 116 and $125 \mathrm{~m}$ and dropping to 0.35 at both the shallow and deep ends. The center of the zone is consistent with selection against hybrids across the ecotone (Endler 1977; Szymura and Barton 1986; Singhal and Moritz 2012).

\section{Low Effective Dispersal across Habitats despite Large Dispersal Potential: Selection across Depths}

Mean estimates of effective dispersal base on LD between pairs of loci at the center of the hybrid zone $(125 \mathrm{~m})$ 

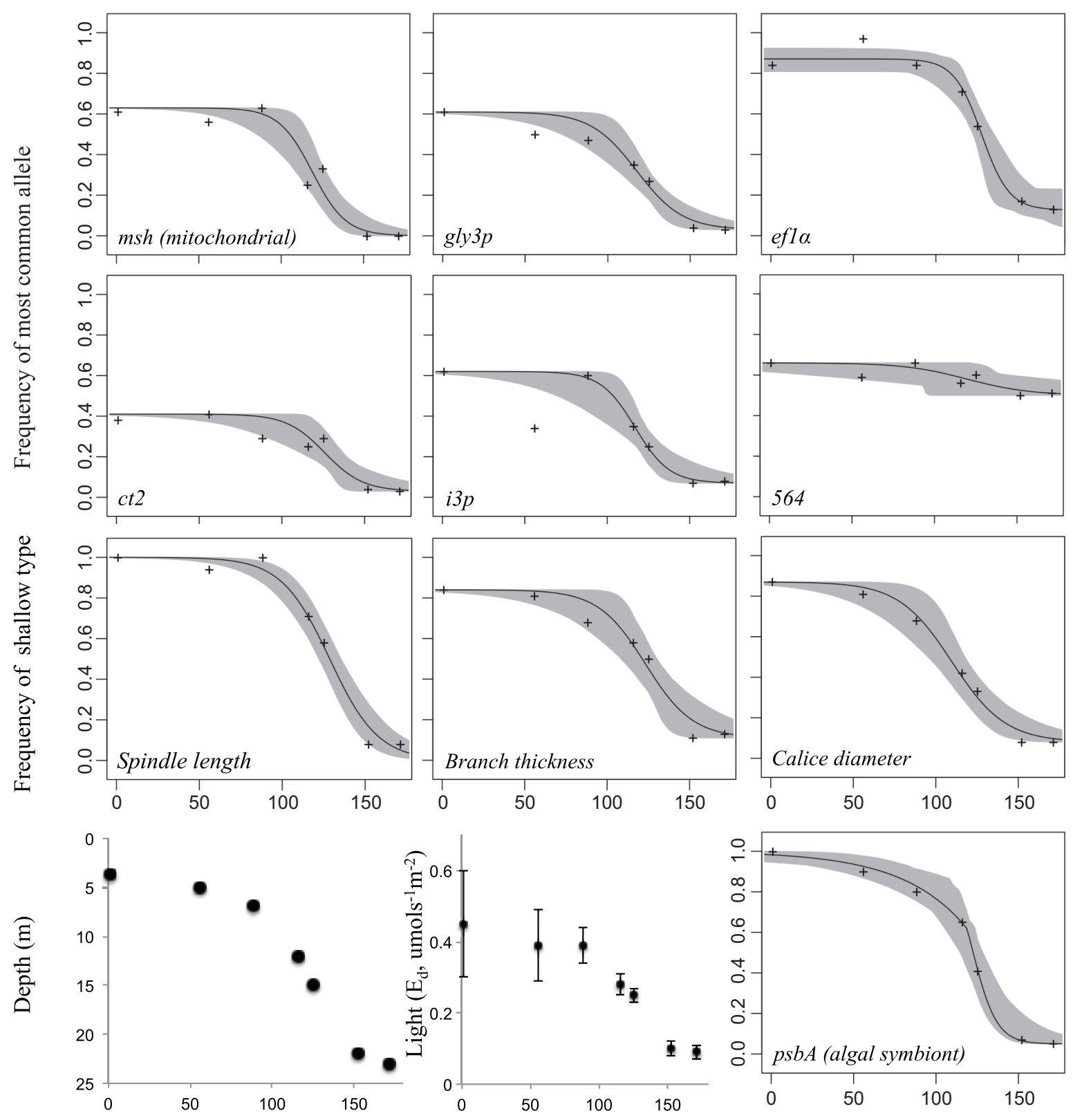

Distance along the transect $(\mathrm{m})$

Figure 2: Maximum likelihood cline shape estimates for the molecular (six) and morphological (three) characters of the coral and for the chloroplast of its algal symbiont (one). Gray areas represent $95 \%$ confidence intervals around the cline fit. Spindle length and calice diameter were estimated in micrometers, and branch thickness was estimated in millimeters. Left and center bottom panels show variation in depth and light across locations.

ranged from 4.9 to $10.0 \mathrm{~m} / \mathrm{generation}$, with a mean value of $7.0 \mathrm{~m} /$ generation. The dispersal potential from parent to offspring estimated from our pairwise $F_{\mathrm{ST}}$ data is 55.52 $\mathrm{km}$ if we use the entire Caribbean area, $17.56 \mathrm{~km}$ if we assume that the species occupies only $10 \%$ of the area, and a conservative $2.39 \mathrm{~km}$ if we assume the high density of 4.38 colonies $/ \mathrm{m}^{2}$ across the entire range. On the basis of this conservative estimate, the effective dispersal across depth is at least 30 times smaller than the dispersal potential of E. flexuosa $(d=0.03)$. While the juveniles we sampled were already segregated to some degree (fig. 1), selection against mismatched genotypes relative to native 
Table 1: Maximum likelihood estimates for cline center and their confidence intervals (range estimated as low and high 2-log-likelihood units)

\begin{tabular}{lll}
\hline Character & \multicolumn{1}{c}{ Center $(\mathrm{m})$} & \multicolumn{1}{c}{ Width $(\mathrm{m})$} \\
\hline$m s h^{\mathrm{a}}$ & $118.90(107.33-127.64)$ & $40.58(19.32-84.24)$ \\
$g l y 3 p^{\mathrm{b}}$ & $117.58(104.37-126.05)$ & $55.62(23.81-110.68)$ \\
$1633^{\mathrm{b}}$ & $125.90(110.07-137.09)$ & $46.07(9.85-120.28)$ \\
$i 3 p^{\mathrm{b}}$ & $116.96(100.99-124.56)$ & $42.08(17.60-122.18)$ \\
$e^{\mathrm{f}} 1 a^{\mathrm{b}}$ & $127.73(121.61-139.04)$ & $33.34(16.76-75.87)$ \\
$564^{\mathrm{b}}$ & $119.80(26.43-198.36)$ & $76.58(.09-229.79)$ \\
Spindle length $^{\mathrm{c}}$ & $128.79(119.16-137.80)$ & $19.05(10.84-72.31)$ \\
Calice diameter $^{\mathrm{c}}$ & $114.89(101.71-119.34)$ & $42.32(25.96-95.04)$ \\
Branch thickness $^{\mathrm{c}}$ & $130.73(113.56-144.86)$ & $25.57(10.42-100.24)$ \\
psbA $^{d}$ & $121.78(116.05-124.17)$ & $29.70(23.38-62.02)$ \\
\hline
\end{tabular}

Note: Shown are selection coefficients for nine characters (mitochondrial DNA [mtDNA], nuclear DNA [nDNA], morphology, and chloroplast DNA [cpDNA] from algal symbiont) as inferred using nonstandardized $(D)$ and standardized $\left(R_{i j}\right)$ linkage disequilibrium with the program Analyse.

a mtDNA.

${ }^{\mathrm{b}} \mathrm{nDNA}$.

c Morphology.

d cpDNA.

ones is high: 0.8 for the deep ecotype in shallow habitats and 0.5 for the shallow ecotype in deep habitats.

\section{Environmental Factors Correlate with the Hybrid Zone Center}

Clines of molecular and morphological characters coincide with variation in depth and light conditions (fig. 2, left and center bottom panels). The zone produces a sharp gradient that separates the shallow and deep forms of $E$. flexuosa at about 116-130 m along the transect, which occurs at depths of 14-16 m, right at the reef slope and coincident with the break from shallow fore reef to a deep fore reef habitat (Ballantine et al. 2008). In Puerto Rico, this ecological transition is accompanied by a rapid change in light (fig. 2, center bottom panel).

\section{No First-Generation Hybrids}

Fifteen (9\%) of the 159 individuals surveyed were identified by NewHybrids as hybrids. No hybrids were seen at the shallowest site (3-4 m deep). The proportions of hybrids at other sites ranged from $4.5 \%$ to $21.0 \%$ but were not statistically different from each other $(P=.6)$. Most hybrids were admixed individuals, with no first-generation hybrids, only one $\mathrm{F}_{2}$ individual, and all others later backcrosses.

\section{Discussion}

The two genetically differentiated but incompletely isolated forms of Eunicea flexuosa meet in a narrow hybrid zone ( $<100 \mathrm{~m}$ lateral distance) that follows light and depth gradients, with clines coincident across morphological and molecular markers. The center of this hybrid zone is characterized by a deficit of heterozygotes, with no first-generation hybrids and most hybrids being later-generation backcrosses. The narrow hybrid zone is maintained by strong selection $(>0.5)$ against juveniles mismatched to the habitat in which they settled. The high selection inferred from colonies at different ages/sizes is consistent with earlier estimates derived from field transplant experiments of adults (Prada et al. 2008; Prada and Hellberg 2013). Even under conservative assumptions about larval dispersal potential, the spatial scale of adaptation to depth in E. flexuosa is at least 30 times smaller than the dispersal potential of the species.

\section{The Eunicea flexuosa Hybrid Zone Is Unusually Narrow for a Marine Broadcaster}

The hybrid zone of E. flexuosa stands among the narrowest hybrid zones characterized, comparable with those of terrestrial snails (Stankowski 2013) and grasshoppers (Kawakami et al. 2009), animals with notably meager dispersal potentials. The narrowness of the hybrid zone is unusual for marine broadcasters, which spawn their gametes and produce larvae capable of dispersing tens of kilometers. This degree of dispersal has few terrestrial parallels, with the best being pollen-producing trees (Schueler and Schlünzen 2006) and pines (Williams 2010) or birds (Payne 1992; Carling et al. 2011). In these, however, hybrid zones exceed the dispersal ability of the hybridizing taxa 

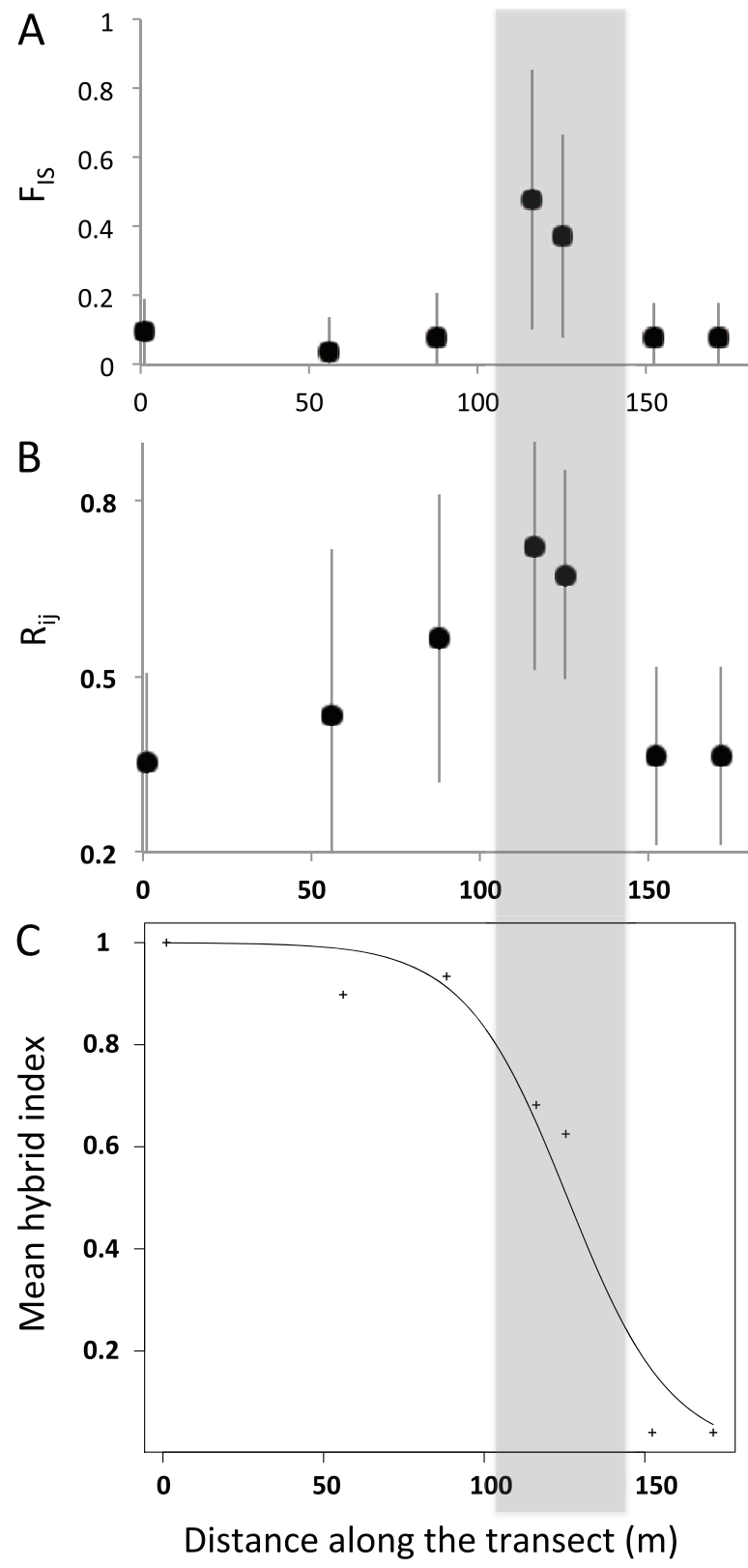

Figure 3: Inbreeding coefficient $\left(F_{\mathrm{IS}} ; A\right)$, standardized linkage disequilibrium $\left(R_{i j} ; B\right)$, and mean hybrid index $(C)$ along the depth gradient. Gray shading indicates the center of the hybrid zone. Linkage disequilibrium is scaled by allele frequencies.

(Carling and Brumfield 2009; Carling et al. 2011; Hamilton et al. 2013).

In contrast, marine broadcasters commonly generate hybrid zones narrower than their dispersal distances and often follow environmental gradients in salinity, temperature, and habitat (Hilbish 1985; Duggins et al. 1995; Gardner 1997). Dispersal potential per se is thus a rather weak predictor of realized gene flow, and factors such as ecological filtering (Marshall et al. 2010) and genomic incompatibilities in hybrids must play a role in shaping the distribution of genetic variation (Burton et al. 2006). This is evidenced by geographic variation in the width of hybrid zones shown in some species. Blue mussels - the most studied hybrid system in the ocean-form multiple hybrid zones across Europe and North America that vary by hundreds of kilometers in width (Hilbish 1985; Gardner 1997; Riginos and Cunningham 2005). Similarly, killifish (Fundulus) generate clines that extend $500 \mathrm{~km}$ near New Jersey (McKenzie 2013) but just $27 \mathrm{~km}$ in Florida (Duggins et al. 1995).

\section{Mechanisms Maintaining the Narrow Eunicea flexuosa Hybrid Zone}

Previously, we used reciprocal transplants of adults to show that immigrant inviability might drive diversification across depths in E. flexuosa (Prada and Hellberg 2013). Differences between juveniles and adults in lineage frequencies (fig. 1) suggest that postrecruitment processes play a role in adult habitat differentiation. Immigrant inviability prevents gene flow and generates the tight hybrid zone we see in E. flexuosa. Because we sampled colonies $<3 \mathrm{~cm}$ tall (about 2 years old), our selection coefficient may be an underestimate, as we missed effects on younger stages. Even under strong immigrant inviability, larval habitat choice may still operate and bias the proportion of initial settlers (Grosberg 1982; Baird et al. 2003). We suspect that strong habitat selection across depths may drive the evolution of habitat choice in corals, as seen in other marine invertebrates (Grosberg 1981).

Habitat choice may indicate phenotype-dependent dispersal to the optimal habitat, which in turn and in addition to selection for local adaptation promotes adaptive divergence (Edelaar and Bolnick 2012). In locally adapted populations, phenotype-dependent gene flow may promote adaptive divergence instead of retarding it, as traditionally assumed for random gene flow (Endler 1975). Phenotypedependent gene flow bypasses the cost of random dispersal to maladaptive habitats (migration load) because nonrandom gene flow is tied to high fitness after settlement, thus increasing genomic divergence associated with habitat performance (Edelaar and Bolnick 2012). Phenotype-dependent dispersal may be particularly important in marine broadcasters such E. flexuosa, in which populations are genetically homogeneous for neutral markers over hundreds to thousands of kilometers (Berntson et al. 2001; Baums et al. 2005; Severance and Karl 2006) but which exhibit larval habitat choice (Baird et al. 2003) and local adaptation at small scales $(<1 \mathrm{~km}$; Prada and Hellberg 2013; Palumbi 2014).

Immigrant inviability across ecological gradients also pre- 
dicts that clines in molecular and morphological variation are scaled by the strength of selection, even under high gene flow, and will coincide with environmental gradients (Endler 1977; Moore and Price 1993). The hybrid zone described here (fig. 2) tightly correlates with a change in depth and light and matches closely with the transition from a shallow gorgonian-dominated habitat to a deep platy-coral environment, separated by a transitional fore reef slope dominated by massive (mostly Orbicella) corals (Ballantine et al. 2008). The direct evidence linking the hybrid zone with environmental variation, the habitat-driven mortality at different age/size classes, and the fitness differential across depths highlight the importance of adaptation to depth in generating and maintaining coral reef diversity.

Ecological factors associated with depth that could cause adaptive divergence include light, food availability, predators, water motion, and sediment transport and composition (Knowlton 1993). Studies of E. flexuosa and close relatives have shown that depth differences may lead to shifts in symbiotic algae (Prada et al. 2014), morphology (Kim et al. 2004; Prada et al. 2008), and feeding strategies (Lasker et al. 1983). Adaptation to depth thus likely entails a multifaceted response, affecting various genomic regions simultaneously. Such coupling between multiple genomic regions shaped by environmental selection suggests that genomic and environmental incompatibilities in hybrids are interconnected and act in concert (Nurnberger et al. 1995).

In addition, adaptation to depth can cause differences in the timing of spawning and assortative mating, which in turn can also reinforce the shallow/deep hybrid zone, as in other systems (Jiggins and Mallet 2000). Differential timing of spawning has been reported in other broadcasting corals (Knowlton et al. 1997; Levitan et al. 2004), and some preliminary evidence suggests that E. flexuosa develop eggs at different times at different depths (Kim et al. 2004). Marine broadcasters also often have fast coevolving sperm-egg-interacting proteins that are highly specific and often driven to diverge interspecifically by positive selection (Swanson and Vacquier 2002; Hellberg et al. 2012). We suggest that habitat selection may initially generate divergence, then genetic incompatibilities and assortative mating build through time and reinforce the depth segregation that we see today in the shallow and deep lineages of E. flexuosa.

\section{Strong Parallel Environmental Gradients Plus Long Prereproductive Selection Generates a Narrow Hybrid Zone despite Large Dispersal Potential}

Two aspects of the biology of E. flexuosa and the environment in which the diverging lineages meet may help generate its narrow cline: (1) sharp and parallel multifac- eted environmental gradients and (2) strong selection by cumulative postsettlement, prereproductive selection.

To generate a narrow stable hybrid zone in a broad disperser, an environmental gradient strong enough to generate local adaptation between populations must be present (Clarke 1966; Slatkin 1975; Endler 1977; Moore 1977). It has been shown empirically and theoretically that sharp clines are generated if the magnitude of selection is strong $(>0.1)$, independent of the amount of gene flow (Endler 1975, 1977). In marine systems, salinity can generate steep (tens of kilometers) clines in both vertebrates (Whitehead et al. 2011) and invertebrates (Gardner 1997; Riginos and Cunningham 2005), while temperature generates broader (hundreds of kilometers) clines (Gardner 1997; Whitehead and Crawford 2006) in the same taxa. In both cases, hybrid zones or locus-specific clines are tightly related to environmental variation, and loci directly under environmental selection haven been identified (Hilbish and Koehn 1984, 1985; Schmidt and Rand 2001; Whitehead et al. 2011).

But perhaps the feature that most promotes the development of a narrow zone is the long postsettlement juvenile period of E. flexuosa. Habitat selection is exceptionally strong in sedentary long-lived organisms like trees and corals, in which a long period of time elapses between dispersal of propagules and the onset of reproduction in sessile adults. Such a long time ( $>20$ years) generates an extended opportunity for selection to act and sort individuals by habitat before they reproduce (Prada and Hellberg 2013). Narrow hybrid zones between long-lived species with high dispersal along steep environmental gradients may be unduly found in long-lived sessile marine broadcasters, such as corals, sea fans, and sponges, but also across elevational gradients in long-lived plants, such as oaks and pines. For example, in Japanese subalpine coniferous forest (Pinus pumila and Pinus parviflora), a hybrid zone forms in just $325 \mathrm{~m} \mathrm{(125} \mathrm{m} \mathrm{in} \mathrm{elevation;}$ Watano et al. 2004), a pattern echoed by pines in China (Li et al. 2010) and the Rocky Mountains (Rehfeldt 1988).

Long-lived species with high dispersal potential can thus generate narrow hybrid zones along steep environmental gradients, a pattern that the shift in juvenile frequencies we document here suggests can arise from immigrant inviability. The strong diversifying selection across these gradients may explain the large number of sibling species that segregate by depth (Knowlton 1993) and is consistent with divergence occurring at spatial scales far smaller than previously considered.

\section{Acknowledgments}

Earlier versions of the manuscript were improved by comments from T. Day, M. Kelly, E. Svensson, and two anon- 
ymous reviewers. We thank the Department of Marine Sciences, University of Puerto Rico at Mayagüez (R. Appeldorn, I. Bejarano, D. Beltrán, M. Cardona, N. Schizas, and P. Yoshioka; NOAA-NA06NOS4780190), and the Socolofsky Microscopy Center, Louisiana State University (LSU). We thank S. Baird, G. Derryberry, and S. Singhal for help with HZAR and Analyse. Discussions with M. Debiasse and participants of the 2010 Summer School in Speciation Genetics (Swiss Federal Institute of Aquatic Science and Technology, Kastanienbaum, Lucerne, Switzerland) improved this study. This work was supported by a Lerner Gray Grant Award from the American Museum of Natural History, a Rosemary Grant Research Award from the Society for the Study of Evolution, and a Grant Research Award from the Society of Systematic Biologists. C.P. has been supported by Huel Perkins and Dissertation Year Fellowships from LSU. Partial funds came from the Department of Biological Sciences, LSU; Doctoral Dissertation Improvement Grants in the Directorate for Biological Sciences (DDIG), National Science Foundation (NSF), awarded to C.P. and M.E.H. (DEB-1311579); and an NSF grant to I. B. Baums and M.E.H. (OCE-0550270).

\section{Literature Cited}

Alino, P., and J. Coll. 1989. Observations of the synchronized mass spawning and postsettlement activity of octocorals on the Great Barrier Reef, Australia: biological aspects. Bulletin of Marine Science 45:697-707.

Anderson, E., and E. Thompson. 2002. A model-based method for identifying species hybrids by using multilocus genetic data. Genetics 160:1217-1229.

Baird, A., R. Babcock, and C. Mundy. 2003. Habitat selection by larvae influences the depth distribution of six common coral species. Marine Ecology Progress Series 252:289-293.

Baldeck, C. A., K. E. Harms, J. B. Yavitt, R. John, B. L. Turner, R. Valencia, H. Navarrete, et al. 2013. Habitat filtering across tree life stages in tropical forest communities. Proceedings of the Royal Society B: Biological Sciences 280:20130548.

Ballantine, D. L., R. S. Appeldoorn, and P. Yoshioka. 2008. Biology and ecology of Puerto Rican coral reefs. Pages 375-406 in B. M. Riegl and R. E. Dodge, eds. Coral reefs of the USA. Springer, Netherlands.

Barton, N. H., and S. Baird. 1998. Analyse 1.10. http://archive.bio .ed.ac.uk/software/Mac/Analyse/index.html. Accessed October 2, 2014.

Barton, N. H., and K. S. Gale. 1993. Genetic analysis of hybrid zones. Pages 13-46 in R. G. Harrison, ed. Hybrid zones and the evolutionary process. Oxford University Press, New York.

Baums, I. B., M. W. Miller, and M. E. Hellberg. 2005. Regionally isolated populations of an imperiled Caribbean coral, Acropora palmata. Molecular Ecology 14:1377-1390.

Bayer, F. M. 1961. The shallow-water Octocorallia of the West Indian region: a manual for marine biologists. M. Nijhoff, The Hague.

Beiring, E. A., and H. R. Lasker. 2000. Egg production by colonies of a gorgonian coral. Marine Ecology Progress Series 196:169-177.
Berntson, E. A., F. M. Bayer, A. G. McArthur, and S. C. France. 2001. Phylogenetic relationships within the Octocorallia (Cnidaria: Anthozoa) based on nuclear 18S rRNA sequences. Marine Biology 138:235-246.

Burke, L., and J. Maidens. 2004. Reefs at risk. World Resources Institute, Washington, DC.

Burton, R. S., C. K. Ellison, and J. S. Harrison. 2006. The sorry state of $\mathrm{F}_{2}$ hybrids: consequences of rapid mitochondrial DNA evolution in allopatric populations. American Naturalist 168(suppl.):S14S24.

Carling, M. D., and R. T. Brumfield. 2009. Speciation in Passerina buntings: introgression patterns of sex-linked loci identify a candidate gene region for reproductive isolation. Molecular Ecology 18:834-847.

Carling, M. D., L. G. Serene, and I. J. Lovette. 2011. Using historical DNA to characterize hybridization between Baltimore (Icterus galbula) and Bullock's (Icterus bullockii) orioles. Auk 128:61-68.

Carlon, D. B. 2002. Production and supply of larvae as determinants of zonation in a brooding tropical coral. Journal of Experimental Marine Biology and Ecology 268:33-46.

Clarke, B. 1966. The evolution of morpho-ratio clines. American Naturalist 100:389-402.

Coffroth, M. A., and H. R. Lasker. 1998. Larval paternity and male reproductive success of a broadcast-spawning gorgonian, Plexaura kuna. Marine Biology 131:329-337.

Coffroth, M. A., S. R. Santos, and T. L. Goulet. 2001. Early ontogenetic expression of specificity in a cnidarian-algal symbiosis. Marine Ecology Progress Series 222:85-96.

Connell, J. H. 1972. Community interactions on marine rocky intertidal shores. Annual Review of Ecology and Systematics 3:169192.

Darwin, C. 1859 . On the origin of species by means of natural selection, or the preservation of favored races in the struggle for life. J. Murray, London.

Derryberry, E. P., G. E. Derryberry, J. M. Maley, and R. T. Brumfield. 2014. HZAR: hybrid zone analysis using an R software package. Molecular Ecology Resources 14:652-663.

Drummond, A. J., B. Ashton, M. Cheung, J. Heled, M. Kearse, R. Moir, S. Stones-Havas, T. Thierer, A. Wilson. 2009. Geneious v4.5.4. http://www.geneious.com.

Duggins, J. C., A. Karlin, T. Mousseau, and K. Relyea. 1995. Analysis of a hybrid zone in Fundulus majalis in a northeastern Florida ecotone. Heredity 74:117-128.

Edelaar, P., and D. I. Bolnick. 2012. Non-random gene flow. Trends in Ecology and Evolution 27:659-665.

Endler, J. A. 1975. Gene flow and population differentiation. Science 179:243-250.

- 1977. Geographic variation, speciation, and clines. Princeton University Press, Princeton, NJ.

- 1979. Gene flow and life history patterns. Genetics 93:263284.

Flot, J.-F. 2007. Champuru 1.0: a computer software for unraveling mixtures of two DNA sequences of unequal lengths. Molecular Ecology Notes 6:974-977.

France, S. C., and L. L. Hoover. 2001. Analysis of variation in mitochondrial DNA sequences (ND3, ND4L, MSH) among Octocorallia (=Alcyonaria) (Cnidaria: Anthozoa). Bulletin of the Biological Society of Washington 10:110-118.

Gardner, J. P. A. 1997. Hybridization in the sea. Pages 1-78 in J. H. 
S. Blaxter and A. J. Southward, eds. Advances in marine biology. Academic Press, London.

Goreau, T. F. 1959. The ecology of Jamaican coral reefs. I. Species composition and zonation. Ecology 40:67-90.

Grosberg, R. K. 1981. Competitive ability influences habitat choice in marine invertebrates. Nature 290:700-702.

- 1982. Intertidal zonation of barnacles: the influence of planktonic zonation of larvae on the vertical distribution of adults. Ecology 63:894-899.

Hamilton, J. A., C. Lexer, and S. N. Aitken. 2013. Differential introgression reveals candidate genes for selection across a spruce (Picea sitchensis $\times$ P. glauca) hybrid zone. New Phytologist 197:927-938.

Harrigan, R., M. Mazza, and M. Sorenson. 2008. Computation vs. cloning: evaluation of two methods for haplotype determination. Molecular Ecology Resources 8:1239-1248.

Hartl, D. L. 2000. A primer of population genetics. Sinauer, Sunderland, MA.

Hellberg, M., A. Dennis, P. Arbour-Reily, J. Aagaard, and W. Swanson. 2012. The Tegula tango: a coevolutionary dance of interacting, positively selected sperm and egg proteins. Evolution 66:1681-1694.

Hey, J., and R. Nielsen. 2004. Multilocus methods for estimating population sizes, migration rates and divergence times, with applications to the divergence of Drosophila pseudoobscura and D. persimilis. Genetics 167:747-760.

Hilbish, T. J. 1985. Demographic and temporal structure of an allele frequency cline in the mussel Mytilus edulis. Marine Biology 86: 163-171.

Hilbish, T. J., and R. K. Koehn. 1984. Dominance in physiological phenotypes and fitness at an enzyme locus. Science 229:52-54.

. 1985. The physiological basis of natural selection at the LAP locus. Evolution 39:1302-1317.

Jiggins, C., and J. Mallet. 2000. Bimodal hybrid zones and speciation. Trends in Ecology and Evolution 15:250-255.

Kawakami, T., R. Butlin, M. Adams, D. Paull, and S. Cooper. 2009. Genetic analysis of a chromosomal hybrid zone in the Australian grasshoppers (Vandiemenella, viatica species group). Evolution 63: 139-152.

Kim, E., H. R. Lasker, M. A. Coffroth, and K. Kim. 2004. Morphological and genetic variation across reef habitats in a broadcastspawning octocoral. Hydrobiologia 530/531:423-432.

Kinzie, R. A. 1973. The zonation of West Indian gorgonians. Bulletin of Marine Science 23:93-155.

Knowlton, N. 1993. Sibling species in the sea. Annual Review of Ecology, Evolution, and Systematics 24:189-216.

Knowlton, N., J. L. Mate, H. M. Guzman, R. Rowan, and J. Jara. 1997. Direct evidence for reproductive isolation among the three species of the Montastraea annularis complex in Central America (Panama and Honduras). Marine Biology 127:705-711.

Lasker, H. R., D. Brazeau, J. Calderon, M. Coffroth, R. Coma, and K. Kim. 1996. In situ rates of fertilization among broadcast spawning gorgonians. Biological Bulletin 190:45-55.

Lasker, H. R., M. D. Gottfried, and M. A. Coffroth. 1983. Effects of depth on the feeding capabilities of two octocorals. Marine Biology 73:73-78.

Levitan, D. R. 2004. Density-dependent sexual selection in external fertilizers: variances in male and female fertilization success along the continuum from sperm limitation to sexual conflict in the sea urchin Strongylocentrotus franciscanus. American Naturalist 164: 298-309.

Levitan, D. R., H. Fukami, J. Jara, D. Kline, T. A. McGovern, K. M.
McGhee, C. A. Swanson, et al. 2004. Mechanisms of reproductive isolation among sympatric broadcast-spawning corals of the Montastraea annularis complex. Evolution 58:308-323.

Li, S., Y. Chen, H. Gao, and T. Yin. 2010. Potential chromosomal introgression barriers revealed by linkage analysis in a hybrid of Pinus massoniana and P. hwangshanensis. BMC Plant Biology 10: 37.

Lindtke, D., Z. Gompert, C. Lexer, and C. A. Buerkle. 2014. Unexpected ancestry of Populus seedlings from a hybrid zone implies a large role for postzygotic selection in the maintenance of species. Molecular Ecology 23:4316-4330.

Lowry, D., J. Modliszewski, K. Wrigh, C. Wu, and J. Willis. 2008. The strength and genetic basis of reproductive isolating barriers in flowering plants. Philosophical Transactions of the Royal Society B: Biological Sciences 363:3009-3021.

Maley, J. M. 2012. Ecological speciation of king rails (Rallus elegans) and clapper rails (Rallus longirostris). $\mathrm{PhD}$ diss. Louisiana State University, Baton Rouge.

Marshall, D., K. Monro, M. Bode, M. Keough, and S. Swearer. 2010. Phenotype-environment mismatches reduce connectivity in the sea. Ecology Letters 13:128-140.

McKenzie, J. L. 2013. Genetic characterization of a hybrid zone in killifish (Fundulus heteroclitus): evidence for assortative mating or selection against hybrids. PhD diss. University of British Columbia, Vancouver.

Moore, R. B., K. M. Ferguson, W. K. W. Loh, O. Hoegh-Guldberg, and D. A. Carter. 2003. Highly organized structure in the noncoding region of the $p s b A$ minicircle from clade C Symbiodinium. International Journal of Systematic and Evolutionary Microbiology 53:1725-1734.

Moore, W. S. 1977. An evaluation of narrow hybrid zones in vertebrates. Quarterly Review of Biology 52:263-278.

Moore, W. S., and J. T. Price. 1993. Nature of selection in the northern flicker hybrid zone and its implications for speciation theory. Pages 196-225 in R. G. Harrison, ed. Hybrid zones and the evolutionary process. Oxford University Press, Oxford.

Nosil, P., T. Vines, and D. Funk. 2005. Perspective: reproductive isolation caused by natural selection against immigrants from divergent habitats. Evolution 59:705-719.

Nurnberger, B., N. H. Barton, C. J. MacCallum, J. Gilchrist, and M. Appleby. 1995. Natural selection on quantitative traits in the Bombina hybrid zone. Evolution 49:1224-1238.

Paine, C. E. T., K. E. Harms, and J. Ramos. 2009. Supplemental irrigation increases seedling performance and diversity in a tropical forest. Journal of Tropical Ecology 25:171-180.

Palumbi, S. R., D. J. Barshis, N. Traylor-Knowles, and R. A. Bay. 2014. Mechanisms of reef coral resistance to future climate change. Science 344:895-898.

Payne, R. B. 1992. Indigo bunting. A. Poole, P. Stettenheim, and F. Gill, eds. The birds of North America. Academy of Natural Sciences, Philadelphia, and American Ornithologists' Union, Washington, DC.

Prada, C., and M. E. Hellberg. 2013. Long pre-reproductive selection and divergence by depth in a Caribbean candelabrum coral. Proceedings of the National Academy of Sciences of the USA 119:5360

2014. Data from: Strong natural selection on juveniles maintains a narrow adult hybrid zone in a broadcast spawner. American Naturalist, Dryad Digital Repository, http://dx.doi.org/10.5061 /dryad.983b0. 
Prada, C., S. E. McIlroy, D. M. Beltrán, D. J. Valint, S. A. Ford, M. E. Hellberg, and M. A. Coffroth. 2014. Cryptic diversity hides host and habitat specialization in a gorgonian-algal symbiosis. Molecular Ecology 23:3330-3340.

Prada, C., N. V. Schizas, and P. M. Yoshioka. 2008. Phenotypic plasticity or speciation? a case from a clonal marine organism. BMC Evolutionary Biology 8:47.

Rehfeldt, G. E. 1988. Ecological genetics of Pinus contorta from the Rocky Mountains (USA): a synthesis. Silvae Genetica 37:131-135.

Riginos, C., and C. W. Cunningham. 2005. Invited review: local adaptation and species segregation in two mussel (Mytilus edulis $\times$ M. trossulus) hybrid zones. Molecular Ecology 14:381-400.

Rousset, F. 1997. Genetic differentiation and estimation of gene flow from $F$-statistics under isolation by distance. Genetics 145:12191228.

Rundle, H., and P. Nosil. 2005. Ecological speciation. Ecology Letters 8:336-352.

Schluter, D. 2009. Evidence for ecological speciation and its alternative. Science 323:737-741.

Schmidt, P. S., and D. M. Rand. 2001. Adaptive maintenance of genetic polymorphism in an intertidal barnacle: habitat and life history stage-specific survivorship of Mpi genotypes. Evolution 55: 1336-1344.

Schueler, S., and K. H. Schlünzen. 2006. Modeling of oak pollen dispersal on the landscape level with a mesoscale atmospheric model. Environmental Modeling and Assessment 11:179-194.

Severance, E. G., and S. A. Karl. 2006. Contrasting population genetic structures of sympatric, mass-spawning Caribbean corals 150:5768.

Singhal, S., and C. Moritz. 2012. Strong selection maintains a narrow hybrid zone between morphologically cryptic lineages in a rainforest lizard. Evolution 66:1474-1489.
Slatkin, M. 1975. Gene flow and selection on a two-locus system. Genetics 81:787-802.

Stankowski, S. 2013. Ecological speciation in an island snail: evidence for the parallel evolution of a novel ecotype and maintenance by ecologically dependent postzygotic isolation. Molecular Ecology 22:2726-2741.

Stephens, M., N. Smith, and P. Donnelly. 2001. A new statistical method for haplotype reconstruction from population data. American Journal of Human Genetics 68:978-989.

Swanson, W. J., and V. D. Vacquier. 2002. The rapid evolution of reproductive proteins. Nature Review in Genetics 3:137-144.

Szymura, J., and N. H. Barton. 1986. Genetic analysis of a hybrid zone between the fire-bellied toads, Bombina bombina and B. variegata, near Cracow in southern Poland. Evolution 40:1141-1159.

. 1991. The genetic structure of the hybrid zone between the firebellied toads Bombina bombina and B. variegata: comparisons between transects and between loci. Evolution 45:237-261.

Watano, Y., A. Kanai, and N. Tani. 2004. Genetic structure of hybrid zones between Pinus pumila and P. parviflora var. pentaphylla (Pinaceae) revealed by molecular hybrid index analysis. American Journal of Botany 91:65-72.

Whitehead, A., and D. Crawford. 2006. Neutral and adaptive variation in gene expression. Proceedings of the National Academy of Sciences of the USA 103:5425-5430.

Whitehead, A., J. Roach, S. Zhang, and F. Galvez. 2011. Genomic mechanisms of evolved physiological plasticity in killifish distributed along an environmental salinity gradient. Proceedings of the National Academy of Sciences of the USA 108:6193-6198.

Williams, C. G. 2010. Long-distance pine pollen still germinates after meso-scale dispersal. American Journal of Botany 97:846-855.

Associate Editor: Erik Svensson Editor: Troy Day
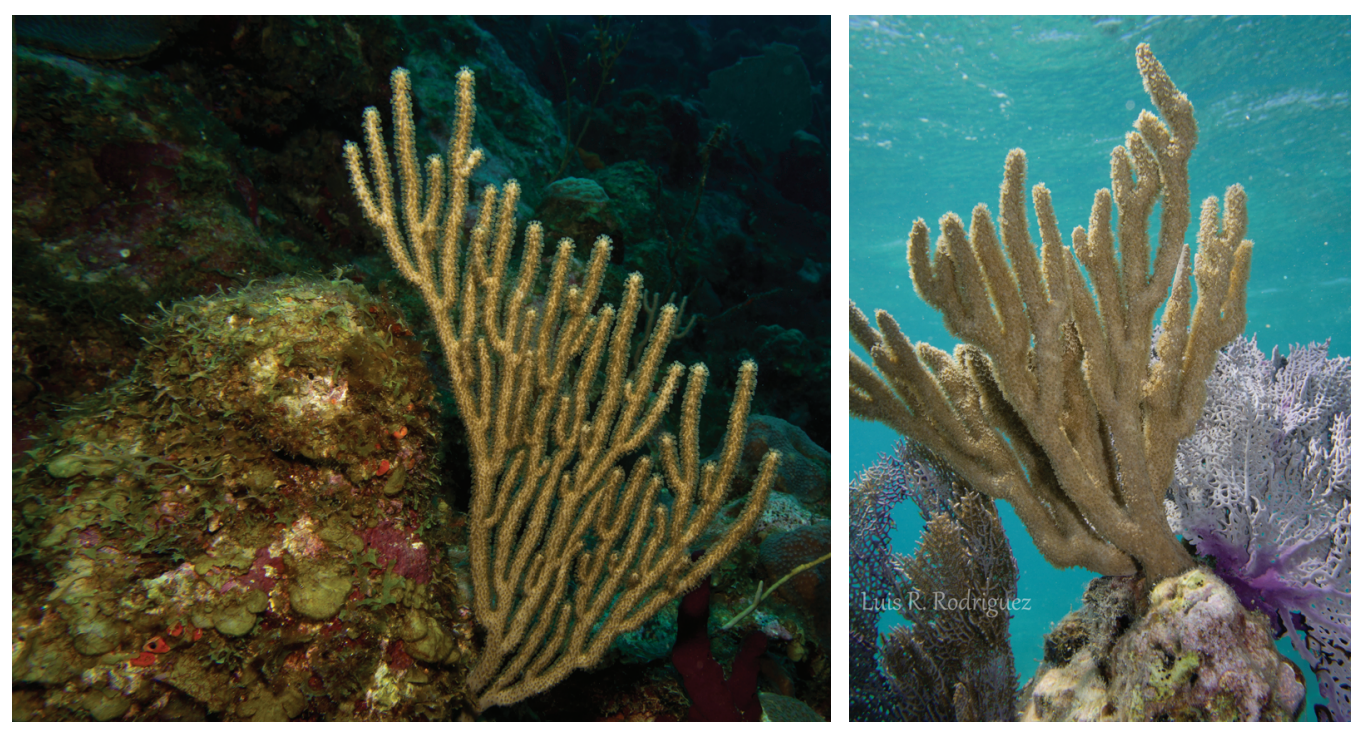

Adult colonies of the candelabrum coral Eunicea flexuosa in shallow environments. Photo by L. R. Rodriguez. 